\title{
Calcium Release from Presynaptic Ryanodine-Sensitive Stores Is Required for Long-Term Depression at Hippocampal CA3-CA3 Pyramidal Neuron Synapses
}

\author{
Vivek K. Unni, ${ }^{1}$ Stanislav S. Zakharenko, ${ }^{1}$ Leonard Zablow, ${ }^{1,3}$ Anthony J. DeCostanzo, ${ }^{2}$ and Steven A. Siegelbaum ${ }^{1,2,3}$ \\ ${ }^{1}$ Center for Neurobiology and Behavior, ${ }^{2}$ Department of Pharmacology, and ${ }^{3}$ Howard Hughes Medical Institute, Columbia University, New York, New York \\ 10032
}

\begin{abstract}
Although $\mathrm{Ca}^{2+}$ release from internal stores has been proposed to be important for the induction of long-term synaptic plasticity, the importance of $\mathrm{Ca}^{2+}$ stores localized in presynaptic terminals remains unclear. Here, we have selectively applied pharmacological antagonists to either the presynaptic or postsynaptic cell in paired whole-cell recordings from hippocampal CA3 pyramidal neurons in slice culture. We demonstrate directly the necessary role of presynaptic, but not postsynaptic, ryanodine-sensitive $\mathrm{Ca}^{2+}$ stores in the induction of NMDA receptor (NMDAR)-dependent long-term depression (LTD). Using two-photon laser scanning microscopy, we further find that release from the ryanodine-sensitive stores during prolonged synaptic stimulation generates a slowly rising $\mathrm{Ca}^{2+}$ signal in the presynaptic terminal that is required for the induction of LTD. Moreover, this form of LTD has a significant presynaptic component of expression because it causes a marked decrease in the rate of release from CA3 neuron presynaptic terminals of FM 1-43, a fluorescent probe of synaptic vesicle cycling. Thus, $\mathrm{Ca}^{2+}$ release from presynaptic ryanodine-sensitive stores is critical in the induction of a presynaptic component of NMDAR-dependent LTD.
\end{abstract}

Key words: long-term depression; CA3; internal calcium stores; ryanodine-sensitive stores; hippocampus; synaptic plasticity

\section{Introduction}

$\mathrm{Ca}^{2+}$ release from internal stores, mediated by either the $\mathrm{IP}_{3}$ receptor $\left(\mathrm{IP}_{3} \mathrm{R}\right)$ or ryanodine receptor $(\mathrm{RyR}) \mathrm{Ca}^{2+}$ release channel, amplifies and dynamically regulates cytosolic $\mathrm{Ca}^{2+}$ levels (Berridge et al., 2003). In neurons, $\mathrm{Ca}^{2+}$ release from internal stores has been implicated in postsynaptic signaling, presynaptic control of transmitter release, and long-term synaptic plasticity (Berridge, 1998; Fitzjohn and Collingridge, 2002), although its role in these events remains controversial. This is partly because of technical difficulties that limit direct measurement of storedependent $\mathrm{Ca}^{2+}$ signals in small dendritic processes and presynaptic terminals in brain slices. Here, we take advantage of recent advances in imaging techniques to investigate the role of $\mathrm{Ca}^{2+}$ release in long-term depression (LTD) at the CA3-CA3 pyramidal neuron synapse in hippocampal slice culture (Montgomery et al., 2001).

A role for $\mathrm{Ca}^{2+}$ release from internal stores has been previously suggested for LTD at several hippocampal synapses (Reyes and Stanton, 1996; Wang et al., 1997; Caillard et al., 2000; Nishiyama et al., 2000). At least two forms of hippocampal LTD have

Received Dec. 18, 2003; revised Sept. 7, 2004; accepted Sept. 9, 2004.

This work was supported in part by National Institutes of Health Grants MH50733 and NS29832. We thank Arnold Kriegstein, Amy MacDermott, Andrew Marks, Patric Stanton, and Tamily Weissman for helpful comments on this manuscript and Paul Pavlidis for helpful advice.

Correspondence should be addressed to Dr. Steven A. Siegelbaum, Center for Neurobiology and Behavior, Columbia University, 722 West 168th Street, New York, NY 10032. E-mail: sas8@columbia.edu.

DOI:10.1523/JNEUROSCI.5583-03.2004

Copyright $\odot 2004$ Society for Neuroscience $\quad$ 0270-6474/04/249612-11\$15.00/0 been identified: an NMDA receptor (NMDAR)-dependent form (Stanton and Sejnowski, 1989; Dudek and Bear, 1992; Mulkey and Malenka, 1992) and a metabotropic glutamate receptor (mGluR)-dependent form (Bolshakov and Siegelbaum, 1994; Oliet et al., 1997). In both cases, a rise in postsynaptic $\mathrm{Ca}^{2+}$ is required for the induction of plasticity (Bolshakov and Siegelbaum, 1994; Oliet et al., 1997). Moreover, at CA3-CA1 synapses in acute hippocampal slices, $\mathrm{IP}_{3} \mathrm{R}$-mediated $\mathrm{Ca}^{2+}$ release in the postsynaptic CA1 pyramidal neuron (Reyes and Stanton, 1996; Wang et al., 1997; Caillard et al., 2000; Nishiyama et al., 2000) and RyR-mediated $\mathrm{Ca}^{2+}$ release in either the postsynaptic CA1 neuron (Reyes and Stanton, 1996; Wang et al., 1997; Caillard et al., 2000; Nishiyama et al., 2000) or presynaptic CA3 neuron (Reyes and Stanton, 1996) have been implicated in the induction of NMDAR-dependent LTD. The importance of $\mathrm{Ca}^{2+}$ stores has also been shown genetically because deletion of the RyR3 ryanodine receptor subunit abolishes LTD at CA3-CA1 synapses (Futatsugi et al., 1999). However, a specific $\mathrm{Ca}^{2+}$ signal attributable to RyR- or $\mathrm{IP}_{3} \mathrm{R}$-mediated $\mathrm{Ca}^{2+}$ release during the induction of LTD has not yet been identified, nor has the presynaptic contribution of $\mathrm{Ca}^{2+}$ stores been directly investigated.

We have focused on the importance of $\mathrm{Ca}^{2+}$ stores in the induction of LTD at the excitatory collateral synapse formed between CA3 pyramidal neurons in organotypic slice cultures of the rat hippocampus (Stoppini et al., 1991; Debanne et al., 1998; Montgomery and Madison, 2002). Dual whole-cell patch-clamp recordings from pairs of synaptically connected CA3 neurons allowed us to deliver pharmacological agents selectively into ei- 
ther the presynaptic or postsynaptic cell. Two-photon laser scanning microscopy (TPLSM) permitted us to image $\mathrm{Ca}^{2+}$ in individual presynaptic terminals of CA3 neurons during the induction of LTD.

Here, we confirm that robust, NMDAR-dependent LTD exists at CA3-CA3 synapses (Montgomery and Madison, 2002) and show that the induction of this LTD requires $\mathrm{Ca}^{2+}$ release from presynaptic ryanodine-sensitive stores. Moreover, we provide direct evidence that NMDAR-dependent LTD produces a change in presynaptic function, based on two-photon imaging of the release of the fluorescent styryl dye FM 1-43 (Betz and Bewick, 1992) from presynaptic terminals. We suggest that the RyRdependent $\mathrm{Ca}^{2+}$ signal may gate the response of the presynaptic terminal to a retrograde message, permitting only those terminals that have been activated to undergo LTD. Given the autoassociative nature of the CA3-CA3 connection, this form of LTD may be required to prevent the saturation of transmission at this synapse because of facilitatory processes such as LTP.

\section{Materials and Methods}

Slice culture preparation. Slice cultures were made using the general membrane insert technique (Stoppini et al., 1991). Postnatal day 8 Sprague Dawley rats were decapitated, and their brains were quickly removed and placed in chilled minimal essential medium (catalog \#12370-037; Invitrogen, San Diego, CA) supplemented with 1\% penicillin-streptomycin solution (catalog \#15140-122; Invitrogen). The hippocampus was carefully dissected and cut into $400-\mu$ m-thick slices using a tissue chopper. Three slices were placed on one Millicell CM membrane insert (catalog \#PICM03050; Millipore, Bedford, MA), the underside of which was bathed in $1 \mathrm{ml}$ of warmed $5 \% \mathrm{CO}_{2}$ equilibrated culture medium [50\% minimal essential medium (catalog \#12370-037; Invitrogen), 25\% HBSS (catalog \#24020-117; Invitrogen), 25\% horse serum (catalog \#A-3311-L; HyClone, Logan, UT), 0.5\% L-glutamine solution (catalog \#25030-081; Invitrogen), and 1\% penicillin-streptomycin solution (catalog \#15140-122; Invitrogen)]. The slice cultures were first placed in a $37^{\circ} \mathrm{C}$ incubator for $2 \mathrm{~d}$ and then moved to a $34^{\circ} \mathrm{C}$ incubator. Slice cultures were fed by exchanging the culture medium ( $1 \mathrm{ml}$; formulation described above) every $2-3 \mathrm{~d}$. Experiments were performed on slice cultures after $1-6$ weeks in vitro.

Electrophysiology. Paired whole-cell recordings were obtained with an Axoclamp-2A amplifier (presynaptic cell; Axon Instruments, Foster City, CA) and an EPC-9 amplifier (postsynaptic cell; HEKA Elektronik, Lambrecht/Pfalz, Germany). Patch pipettes were filled with the following internal solution (in mM): $115 \mathrm{KMeSO}_{4}, 20 \mathrm{KCl}, 10 \mathrm{HEPES}, 4 \mathrm{MgCl}_{2}, 4$ $\mathrm{Na}_{2}$ ATP, $10 \mathrm{NaPhosphocreatine,} 0.4 \mathrm{Na}_{2} \mathrm{GTP}$, and 0.1 EGTA, titrated to $\mathrm{pH}$ 7.2-7.3 with $\mathrm{KOH}$ [all reagents were purchased from Sigma (St. Louis, MO), except KMeSO4 from ICN Biomedicals (Cleveland, OH)]. In some experiments, the internal solution was supplemented with one of the following: $2-5 \mu \mathrm{M}$ thapsigargin (0.1-0.3\% DMSO), $30 \mu \mathrm{M}$ cyclopiazonic acid (CPA; $0.3 \%$ DMSO), $300 \mu \mathrm{M}$ ryanodine $(0.3 \% \mathrm{DMSO})$, $0.3 \%$ DMSO, or $400 \mu \mathrm{M}$ ruthenium red. Recordings were held $\sim 1 \mathrm{hr}$ before application of LTD induction protocols to allow sufficient time for drug diffusion throughout the cell. Based on imaging experiments, in which we tracked the time course of diffusion of the calcium dye Oregon Green BAPTA-1 to presynaptic terminals and distal postsynaptic dendrites, a $1 \mathrm{hr}$ period results in a concentration of dye at distal dendrites and presynaptic terminals equal to $\sim 50-60 \%$ of the concentration in the patch pipette. Because most of the drugs we used were similar in size or smaller than this calcium dye (molecular weight, $1114 \mathrm{Da}$ ), a $1 \mathrm{hr}$ time period should be adequate for a sufficient concentration of drug to reach its target.

Patch pipettes were pulled to resistances between 3 and $6 \mathrm{M} \Omega$, and access resistances of recordings were between 8 and $30 \mathrm{M} \Omega$. Experiments in which postsynaptic access resistance was not stable were not included in the analysis. Monosynaptic connections were identified by their constant short latency $[<3$ msec between action potential (AP) peak and EPSC rise]. Individual slice cultures were cut out of the membrane using a scalpel and placed in a submerged perfusion chamber in artificial CSF (ACSF) solution (in mM: $119 \mathrm{NaCl}, 2.5 \mathrm{KCl}, 1 \mathrm{MgCl}_{2}, 2 \mathrm{CaCl}_{2}, 1.25$ $\mathrm{Na}_{2} \mathrm{HPO}_{4}, 26.2 \mathrm{NaHCO}_{3}$, and 10 glucose) equilibrated with $95 \% \mathrm{O}_{2} / 5 \%$ $\mathrm{CO}_{2}$. Slices were perfused at a rate of $2 \mathrm{ml} / \mathrm{min}$. In some experiments, one of the following drugs was added to the ACSF: $50 \mu \mathrm{M} \mathrm{D}-\mathrm{APV}, 200 \mu \mathrm{M}$ 1-aminoindan-1,5-dicarboxylic acid (AIDA), $5 \mu \mathrm{M}$ nitrendipine, 2-3 $\mu \mathrm{M}$ $\mathrm{CPA}, 50 \mu \mathrm{M}$ nickel chloride, or $10 \mu \mathrm{M}$ ryanodine. In experiments using bath application of CPA and ryanodine, slice cultures were perfused with these agents for 20-30 min before the LTD induction protocol to ensure adequate delivery. All experiments using nitrendipine were conducted in a darkened room with the nitrendipine-containing ACSF shielded from light. Thapsigargin, ryanodine, and ruthenium red were purchased from Calbiochem (La Jolla, CA). CPA and nickel chloride were purchased from Sigma. D-APV, AIDA, and nitrendipine were purchased from Tocris (Bristol, UK).

Baseline recordings were made by firing a single AP in the presynaptic cell at $0.1 \mathrm{~Hz}$ by injecting $10-15 \mathrm{msec}$ current steps ( $1 \mathrm{nA}$ ), while maintaining the postsynaptic cell in voltage-clamp mode at $-70 \mathrm{mV}$. LTD was induced by switching the postsynaptic cell into current-clamp mode and firing the presynaptic cell at $5 \mathrm{~Hz}$ for $3 \mathrm{~min}$ (total, $900 \mathrm{APs}$ ). The recordings were then returned to the baseline configuration for the duration of the recording. Traces were acquired using Pulse (HEKA), digitized at 5 $\mathrm{kHz}$ and filtered at $2 \mathrm{kHz}$. Because of the variability in the size of the unitary EPSC in paired recording experiments, we used a sliding boxcar window to average 20 successive EPSCs (representing a $200 \mathrm{sec}$ time period) and have displayed the mean EPSC amplitude versus time by shifting the boxcar over each successive EPSC. LTD was measured by averaging 20 data points centered on the time point $15 \mathrm{~min}$ after the end of the induction protocol. This analysis was done for each pair, and the average reported is the mean value from the different paired recording experiments. All mean values from paired recording experiments reported either in bar graphs or in the text are calculated from the $15 \mathrm{~min}$ time point, as described above. In some experiments, presynaptic neurons were stimulated using an ACSF-filled glass extracellular electrode placed in the CA3 cell body layer. In extracellular stimulation experiments, LTD was analyzed as the value of the data point $15 \mathrm{~min}$ after the end of the induction protocol. Errors are reported as SEM. Statistical significance was assessed using Student's $t$ test, except as noted in the text and figure legends. All experiments were performed at room temperature.

Imaging. Calcium imaging was performed by patch clamping individual CA3 pyramidal neurons in whole-cell mode using the same internal solution described above, with the following change: EGTA was replaced with $500 \mu \mathrm{M}$ Oregon Green 488 BAPTA-1 (Molecular Probes, Eugene, $\mathrm{OR})$. Based on fluorescence intensity, we estimate that the dye concentration at the presynaptic terminal was $\sim 300 \mu \mathrm{M}$. In some experiments, we used the lower-affinity calcium dye Fluo-5F at a concentration of 300 $\mu \mathrm{M}$ in the patch pipette to explore the effects of buffer affinity and concentration on the measured calcium signals. In experiments in which we examined the importance of calcium stores, the internal solution was supplemented with one of the following: $30 \mu \mathrm{M}$ CPA (0.3\% DMSO), 300 $\mu \mathrm{M}$ ryanodine $(0.3 \% \mathrm{DMSO})$, or $0.3 \%$ DMSO.

After $\sim 1$ hr loading, a visual search of the basal dendritic region of the cell revealed portions of the axonal arbor. Following the course of an axon branch would often lead to presynaptic varicosities along its length. TPLSM was performed using a BX50WI upright microscope with a $60 \times$, 0.9 numerical aperture objective (Olympus, Melville, NY) and a 1024-MP system (Bio-Rad, Hercules, CA) with a Tsunami Ti:sapphire laser (Spectra-Physics, Mountain view, CA) tuned to $812 \mathrm{~nm}$. Images were acquired using LaserSharp software (Bio-Rad).

Each frame encompassing a presynaptic terminal was $128 \times 128$ pixels and was acquired once every $10 \mathrm{sec}$. These sequences of images of fluorescence intensity were exported and analyzed using custom-written software in Interactive Data Language (Research Systems, Boulder, CO) to measure baseline fluorescence and fluorescence changes. One region of interest (ROI) was centered on the terminal and a second ROI off the cell to record the background. This background was subtracted from the terminal signal to obtain the fluorescence value. Fast and slow phases of the calcium rise were measured as the difference between the fluorescence values at time points specified (see Fig. $4 E$ ). For each trace, fluo- 
rescence values for three consecutive time points (10 sec intervals) were averaged during the baseline (indicated by "1") (see Fig. $4 E$ ), at the peak of the fast phase (" 2 "), and at the end of the slow phase (" 3 ") during the $5 \mathrm{~Hz}$ train and after decay of the $\mathrm{Ca}^{2+}$ signal back to baseline after the train ("4"). The amplitude of the fast phase was measured as the difference between the resultant values at times 2 and 1 (fast phase, 2-1). The amplitude of the slow phase was measured as the difference between the resultant average values at times 3 and 2 (slow phase, 3-2). All averages reported are the mean value of the different experiments, and the error is SEM.

Preparation, acquisition, and analysis of FM 1-43 imaging data were performed using a protocol similar to one published previously (Zakharenko et al., 2001). Slice cultures were loaded by bath application of FM 1-43 (25 $\mu \mathrm{M})$ for 2 min with no stimulation, followed by a 2 min loading stimulation $(10 \mathrm{~Hz})$. After a total of 4 min of exposure to FM 1-43, slices were washed with ACSF containing the sulfonated $\beta$-cyclodextrin ADVASEP-7 (100 $\mu \mathrm{M}$; Cydex, Overland Park, KS) for 20 min to remove any extracellular dye (Kay et al., 1999). Dye release was then determined using $1.5 \mathrm{~Hz}$ stimulation in the continued presence of ADVASEP-7, following the same protocol published previously (Zakharenko et al., 2001).
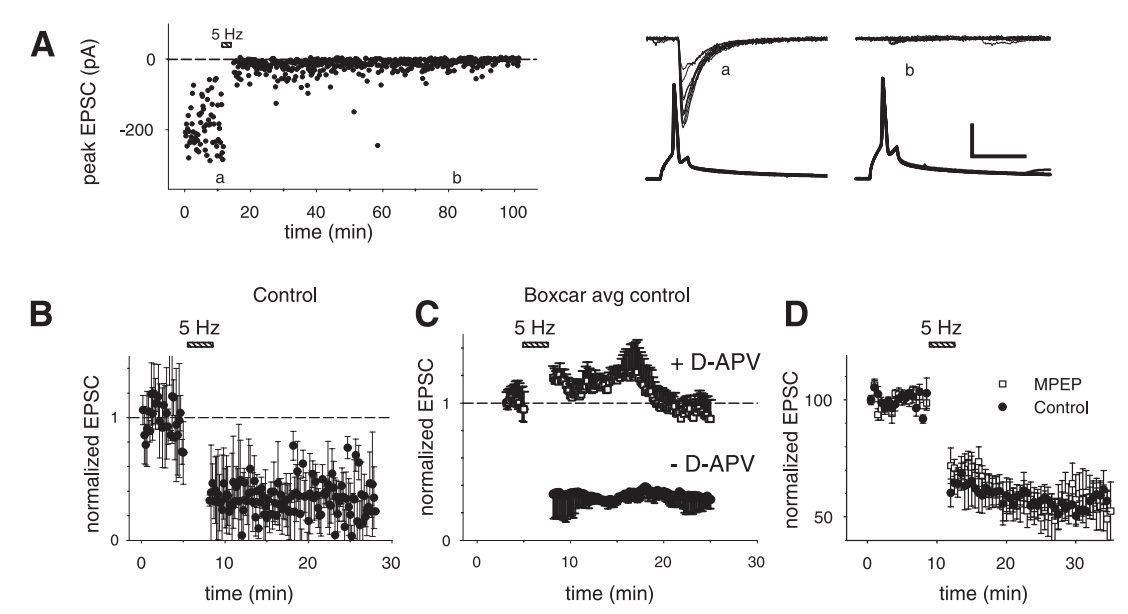

Figure 1. CA3-CA3 synapses exhibit NMDAR-dependent LTD. A, Left, Peak EPSCs recorded from a synaptically connected pair of CA3-CA3 pyramidal neurons before and after induction of LTD (induction protocol shown by striped bar). Letters a and $b$ mark time periods during the recording from which sample traces are shown (on the right). Right, Presynaptic and postsynaptic responses before (a) and after (b) induction of LTD. The bottom traces are current-clamp records showing an overlay of 10 consecutive APs elicited in the presynaptic cell by current injection. The top traces are voltage-clamp records $\left(V_{\mathrm{m}}=-70 \mathrm{mV}\right)$ from the postsynaptic cell showing an overlay of 10 consecutive EPSCs. Calibration: vertical, $40 \mathrm{mV}, 100 \mathrm{pA}$; horizontal, $20 \mathrm{msec}$. $B$, Averaged (normalized) peak EPSC during experiment before and after LTD induction ( $n=11$ pairs). C, Sliding boxcar average (window size, 20 points) of data in the presence (top trace) and absence (bottom trace) of $50 \mu \mathrm{M}$ D-APV. D, LTD at CA3-CA3 synapses does not require activation of mGluR5 receptors. Averaged (normalized) peak EPSCs before and after induction of LTD (induction stimulation shown by bar) in the presence (open squares; $n=6$ ) and absence (closed circles; $n=6$ ) of $10 \mu \mathrm{M}$ MPEP. In this experiment, extracellular field stimulation was used to elicit EPSCs and induce LTD. No sliding boxcar was used.

\section{Results}

NMDAR-dependent LTD is present at CA3-CA3 synapses

Although LTD has been documented and studied at a variety of central synapses, relatively little is known about LTD at recurrent CA3-CA3 synapses in the hippocampus. We recorded from pairs of synaptically connected CA3-CA3 pyramidal neurons in organotypic slice cultures of the rat hippocampus using a protocol similar to that developed by Madison and colleagues (Pavlidis and Madison, 1999; Pavlidis et al., 2000; Montgomery et al., 2001). Stimulation of the presynaptic cell that evoked a single AP elicited an EPSC in the postsynaptic cell. The amplitude of this EPSC was quite variable (range, $\sim 10-300 \mathrm{pA}$ ), even in a single synaptic pair, most likely because of the probabilistic nature of release from a relatively small number of presynaptic terminals (Fig. 1A, left).

When the presynaptic neuron was stimulated at a low frequency of $0.1 \mathrm{~Hz}$, the mean amplitude of the postsynaptic response was stationary over time (Fig. $1 A$, left). However, when we stimulated the presynaptic neuron at a frequency of $5 \mathrm{~Hz}$ for a period of $3 \mathrm{~min}$ ( $900 \mathrm{APs}$ ), a protocol used to evoke LTD at CA3-CA1 synapses in acute hippocampal slices (Bolshakov and Siegelbaum, 1994), we observed a robust and long-lasting decrease in the size of the evoked EPSC that lasted at least $30 \mathrm{~min}$ (Fig. 1A). On average, $15 \mathrm{~min}$ after the induction of LTD, the magnitude of the evoked EPSC was significantly reduced to $32 \pm$ $7 \%(n=11$ pairs; $p<0.001)$ of its baseline value (Fig. $1 B, C$; see Fig. $3 C$ ). Because of the variability in the size of the unitary EPSC, we used a boxcar average to display the time course of the EPSC amplitude during the experiments (Fig. 1C). LTD was only observed when the postsynaptic cell was allowed to depolarize under currentclamp conditions during the induction protocol; when the postsynaptic cell was voltage clamped to $-70 \mathrm{mV}$ during the induction protocol, no LTD was observed (data not shown). This result indi- cates that the induction of LTD at CA3-CA3 synapses requires postsynaptic activity.

To distinguish whether this form of LTD requires NMDAR or mGluR activation, we applied specific pharmacological antagonists. When the $5 \mathrm{~Hz}$ stimulation protocol was applied in the presence of the NMDAR antagonist D-APV $(50 \mu \mathrm{M})$, the induction of LTD was blocked. The size of the evoked EPSC was not significantly different from its baseline value before the $5 \mathrm{~Hz}$ stimulation protocol (EPSC amplitude was $94 \pm 23 \%$ of baseline; $n=5$ pairs; $p>0.33$ ) (Fig. $1 C$; see Fig. $3 C$ ). In contrast, inhibition of group I mGluRs using either the mGluR5 antagonist 2-methyl6-(phenylethynyl)-pyridine (MPEP; $10 \mu \mathrm{M}$ ) (Fig. 1D) (Gasparini et al. 1999) or the mGluR1 antagonist AIDA (200 $\mu \mathrm{M})$ (see Fig. 3C) (Moroni et al., 1997) had no effect on the magnitude of LTD measured $15 \mathrm{~min}$ after its induction. Thus, in the presence of either MPEP or AIDA, the $5 \mathrm{~Hz}$ stimulation reduced the EPSP to $54 \pm 9 \%$ (Fig. $1 D)(p<0.05 ; n=6)$ or $48 \pm 18 \%$ of baseline (see Fig. $3 C)(p<0.05, n=3)$, respectively. This is in agreement with the recent findings of Montgomery and Madison (2002) that CA3-CA3 LTD induced by a prolonged $15 \min$ period of $1 \mathrm{~Hz}$ stimulation is NMDAR dependent but mGluR independent.

\section{LTD depends on ryanodine-sensitive $\mathrm{Ca}^{2+}$ stores}

Although the presence of $\mathrm{Ca}^{2+}$ stores and their role in synaptic plasticity is well documented at parallel fiber-Purkinje cell synapses (Finch and Augustine, 1998; Inoue et al., 1998; Takechi et al., 1998; Daniel et al., 1999) and in the generation of largeamplitude miniature IPSCs (Llano et al., 2000) in the cerebellum, their importance at pyramidal neuron synapses in the hippocampus is more controversial (Harvey and Collingridge, 1992; Emptage et al., 1999, 2001; Nakamura et al., 1999; Svoboda and Mainen, 1999; Rose and Konnerth, 2001). We have therefore tested for the presence and role of $\mathrm{Ca}^{2+}$ stores in the induction of LTD at the CA3-CA3 synapse. First, we used a pharmacological 

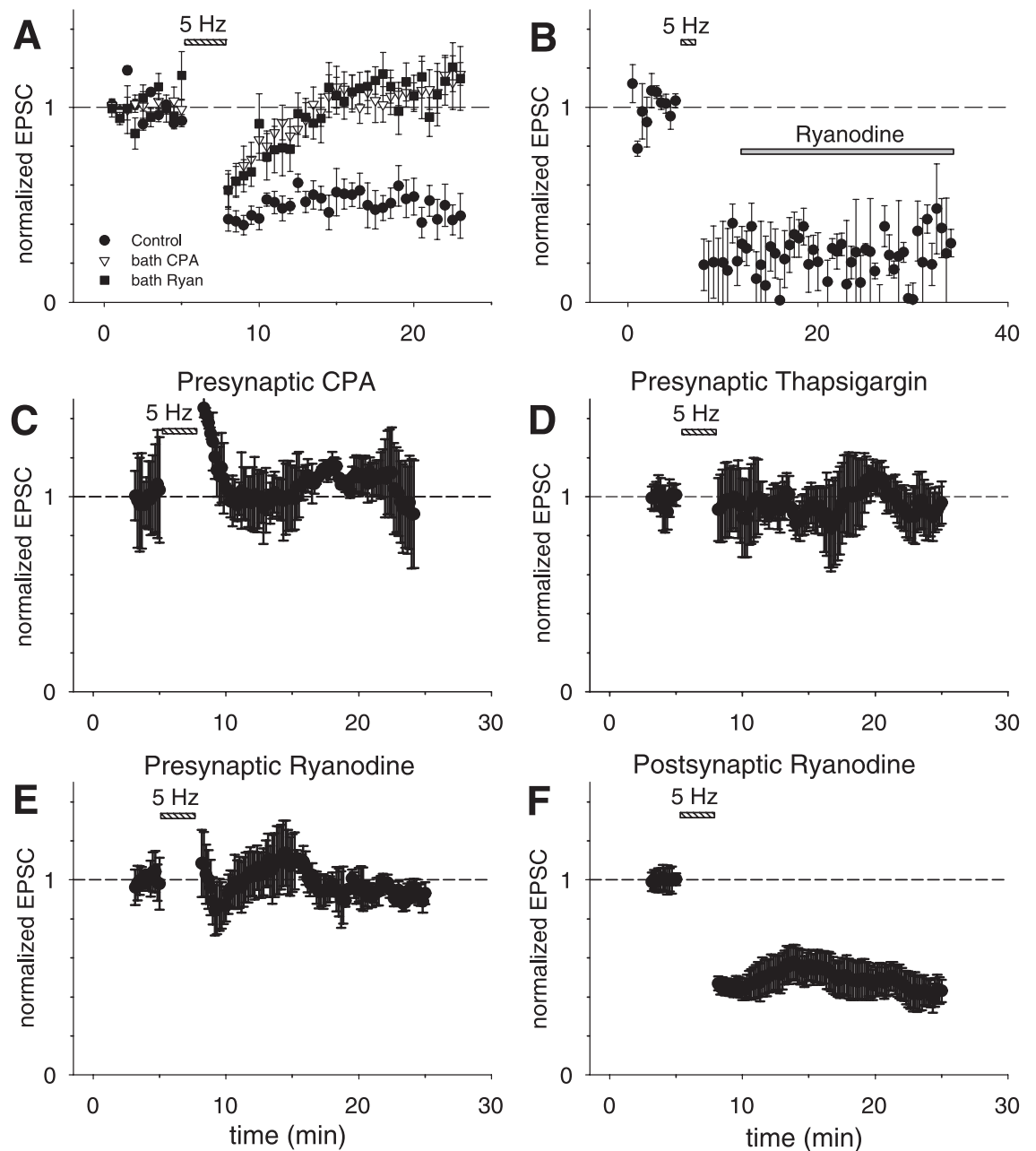

Figure 2. LTD requires presynaptic, but not postsynaptic, ryanodine-sensitive $\mathrm{Ca}^{2+}$ stores. $A$, Average (normalized) peak EPSC elicited by extracellular stimulation before and after LTD induction in normal external solution (filled circles; $n=8$ cells), in presence of external CPA (2-3 $\mu$ m; open inverted triangles; $n=10$ cells), or in presence of external ryanodine ( $10 \mu \mathrm{m}$; filled squares; $n=8$ cells). B, Bath application of ryanodine ( $10 \mu \mathrm{m} ; n=4$ cells) 5 min after the end of the LTD induction protocol does not inhibit LTD. $C-F$, Results from boxcar averaged paired recordings showing effects of selective presynaptic or postsynaptic application of antagonists through recording electrodes. C, Presynaptic application of (PA (30 $\mu \mathrm{m} ; n=4$ pairs). D, Presynaptic application of thapsigargin ( $2-5 \mu \mathrm{m} ; n=5$ pairs). $E$, Presynaptic application of ryanodine (300 $\mu \mathrm{m} ; n=4$ pairs). F, Postsynaptic application of ryanodine (300 $\mu \mathrm{m} ; n=4$ pairs).

approach, involving bath application of $\mathrm{Ca}^{2+}$ store antagonists and extracellular field stimulation, previously used to demonstrate a role for $\mathrm{Ca}^{2+}$ release in the induction of LTD at CA3-CA1 synapses (Reyes and Stanton, 1996).

In these pharmacological experiments, we used extracellular field stimulation of CA 3 inputs at $5 \mathrm{~Hz}$ for $3 \mathrm{~min}$, which produced a robust LTD of very similar magnitude to that obtained using paired recordings as described above. On average, the evoked EPSC was reduced to $44 \pm 6 \%$ of its baseline value 15 min after induction of LTD $(n=8$ cells; $p<0.0001)$ (Fig. $2 A)$. To test for a role of $\mathrm{Ca}^{2+}$ stores in LTD, we applied the LTD induction protocol in the presence of CPA $(2-3 \mu \mathrm{M})$, an inhibitor of the smooth endoplasmic reticulum $\mathrm{Ca}^{2+}$-ATPase (SERCA) pump that depletes both ryanodine-sensitive and $\mathrm{IP}_{3}$-sensitive stores (Kurebayashi and Ogawa, 1991). Under these conditions, the induction of LTD was blocked. The size of the evoked EPSC measured $15 \mathrm{~min}$ after the induction protocol was not significantly different from the baseline EPSC amplitude (117 $\pm 11 \%$ of baseline; $n=10$ cells; $p>0.15$ ) (Fig. $2 A$ ).
We next investigated whether ryanodinesensitive $\mathrm{Ca}^{2+}$ stores are involved in the induction of LTD, as has been previously shown for CA3-CA1 synapses (Reyes and Stanton, 1996; Wang et al., 1997; Caillard et al., 2000; Nishiyama et al., 2000). When the $5 \mathrm{~Hz}$ stimulation protocol was applied in the presence of $10 \mu \mathrm{M}$ ryanodine, a concentration that depresses $\mathrm{Ca}^{2+}$ release selectively from ryanodine-sensitive stores (Zucchi and Ronca-Testoni, 1997), LTD was inhibited. The size of the evoked EPSC measured $15 \mathrm{~min}$ after the induction protocol was not significantly different from the baseline value $(115 \pm 16 \%$ of baseline; $n=8$ cells; $p>0.25$ ) (Fig. $2 A$ ). To distinguish whether ryanodine-sensitive stores are necessary for the induction or expression of LTD, we applied ryanodine to the slice $5 \mathrm{~min}$ after the end of the induction protocol. This treatment did not reverse LTD. Thus, the magnitude of the EPSC remained depressed at $33 \pm 9 \%$ of its baseline value $15 \mathrm{~min}$ after the induction protocol $(n=4$; $p<0.001)$ (Fig. $2 B)$. This finding is consistent with a previous study at CA3-CA1 synapses that demonstrated a requirement for ryanodine-sensitive stores during the induction, but not the expression, of LTD (Reyes and Stanton, 1996). Taken together, these experiments strongly suggest that ryanodine-sensitive $\mathrm{Ca}^{2+}$ stores are required for LTD induction at CA3-CA3 synapses.

\section{Presynaptic, but not postsynaptic,} ryanodine-sensitive stores are required for LTD

Studies using bath application of $\mathrm{Ca}^{2+}$ store antagonists cannot determine whether the stores important for LTD are located presynaptically, postsynaptically, or in glia, all of which contain internal $\mathrm{Ca}^{2+}$ stores that are thought to affect synaptic transmission (Reyes and Stanton, 1996; Wang et al., 1997; Emptage et al., 1999, 2001; Llano et al., 2000; Liang et al., 2002). Here, we have tested directly the potential presynaptic role of ryanodine-sensitive $\mathrm{Ca}^{2+}$ stores required for the induction of LTD by applying drugs to the presynaptic cell through the wholecell recording electrode.

Our experiments provide several lines of evidence that indicate that presynaptic ryanodine-sensitive $\mathrm{Ca}^{2+}$ stores are necessary for the induction of LTD. First, when we applied to the presynaptic cell CPA (at a concentration of $30 \mu \mathrm{M}$ in the presynaptic electrode), the induction of LTD was blocked; the average evoked EPSC measured $15 \mathrm{~min}$ after the induction protocol was $101 \pm 24 \%$ of baseline ( $n=4$ pairs; $p>0.70$ ) (Figs. $2 C, 3 C)$. In contrast, inclusion of the DMSO vehicle (see Materials and Methods) by itself in the presynaptic electrode had no effect on LTD; the average EPSC measured $15 \mathrm{~min}$ after the induction protocol was reduced to $40 \pm 14 \%$ of baseline $(n=4$ pairs; $p<0.001)$. Second, presynaptic application of another SERCA pump inhib- 
A
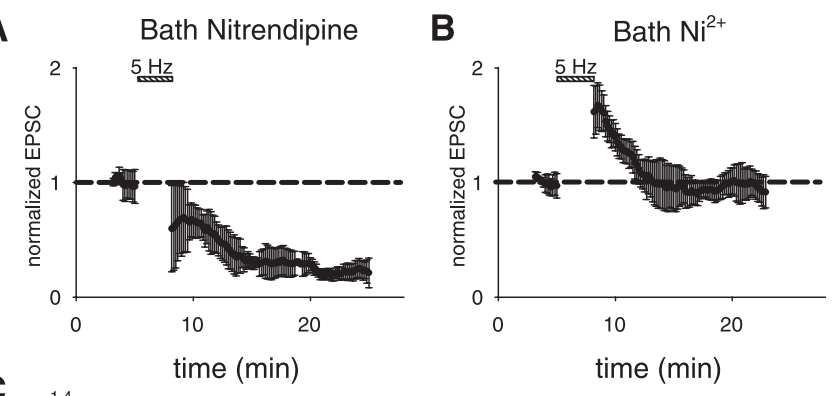

C

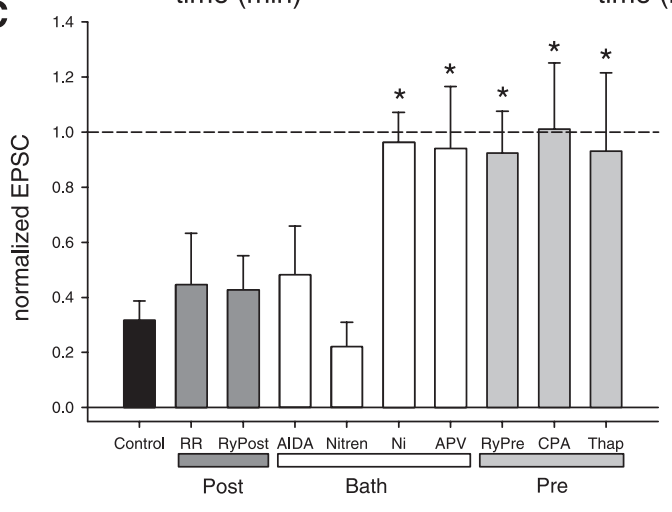

Figure 3. Pharmacological analysis of effects of calcium channel antagonists, glutamate receptor antagonists, and disruption of calcium stores on induction of LTD. $A, B$, Results from boxcar averaged paired recordings showing effects of selective voltage-gated calcium channel antagonist. $A$, Bath applied nitrendipine $(5 \mu \mathrm{M})$ does not prevent the induction of $\operatorname{LTD}(n=3$ pairs). $B$, Bath applied Ni ${ }^{2+}(50 \mu \mathrm{m})$ prevents the induction of LTD ( $n=6$ pairs). C, Summary of pharmacology experiments. Each bar plots mean reduction in EPSC after induction of LTD. Error bars indicate SEM. Control, Normal extent of LTD in the absence of pharmacological agents; RR, LTD with postsynaptic ruthenium red ( $400 \mu \mathrm{m} ; n=3$ ); RyPost, LTD with postsynaptic ryanodine (300 $\mu \mathrm{m} ; n=4)$; AIDA, LTD with bath-applied AIDA (200 $\mu \mathrm{m} ; n=3)$; Nitren, LTD with bath-applied nitrendipine $(5 \mu \mathrm{m} ; n=3)$; Ni, LTD with bath-applied $\mathrm{Ni}^{2+}(50 \mu \mathrm{m} ; n=6) ; \mathrm{APV}$, LTD with bath-applied D-APV (50 $\mu \mathrm{m} ; n=5$ ); RyPre, LTD with presynaptic ryanodine (300 $\mu \mathrm{m}$; $n=4)$; (PA, LTD with presynaptic CPA $(30 \mu \mathrm{m} ; n=4)$; Thap, LTD with presynaptic thapsigargin $(2-5 \mu \mathrm{m} ; n=5)$. The asterisk indicates that an agent caused a significant inhibition in the amount of LTD (ANOVA, $p<0.002$; with post hoc Bonferroni test, $p<0.05$ ).

itor, thapsigargin $(2-5 \mu \mathrm{M})$, also prevented the induction of LTD, with an average EPSC response equal to $93 \pm 28 \%$ of baseline $(n=5$ pairs; $p>0.53)$ (Figs. $2 D, 3 C)$. Finally, application of ryanodine (300 $\mu \mathrm{M}$ in the pipette) to the presynaptic cell also blocked the induction of LTD, with an average response that was $92 \pm 15 \%$ of baseline $(n=5$ pairs; $p>0.55$ ) (Figs. $2 E, 3 C)$. (We used $300 \mu \mathrm{M}$ ryanodine in the pipette because $10 \mu \mathrm{M}$, the concentration used in bath applications, was ineffective, presumably because of loss of the membrane-permeable compound as it diffused from the whole-cell pipette in the soma down the axon to the presynaptic terminals).

In contrast to the inhibitory effect of presynaptic ryanodine, application of ryanodine ( $300 \mu \mathrm{M}$ in the postsynaptic electrode) to the postsynaptic cell did not alter the induction of LTD. The average EPSC $15 \mathrm{~min}$ after the induction protocol was reduced to $43 \pm 12 \%$ of baseline $(n=4$ pairs; $p<0.01$ ) (Figs. $2 F, 3 C)$. The lack of an effect of postsynaptic ryanodine is unlikely to reflect its failure to diffuse into the dendrites because we observed rapid diffusion of a variety of dyes (see below) into distal dendrites and presynaptic ryanodine was effective in blocking LTD. In addition, we found that postsynaptic application of ruthenium red (400 $\mu \mathrm{M}$ in the pipette), a hydrophilic membrane-impermeant inhibitor of $\mathrm{Ca}^{2+}$ release from ryanodine-sensitive stores that prevents LTD at other hippocampal synapses (Caillard et al., 2000), failed to block LTD (EPSC reduced to $45 \pm 19 \%$ of baseline; $n=3, p<$
0.01) (Fig. 3C). These experiments strongly suggest that the requirement for functional ryanodine-sensitive $\mathrm{Ca}^{2+}$ stores during the induction of CA3-CA3 LTD is limited to the presynaptic cell. A lack of involvement of postsynaptic ryanodine-sensitive $\mathrm{Ca}^{2+}$ stores in LTD was previously reported at CA3-CA1 synapses (Reyes and Stanton, 1996; cf. Nishiyama et al., 2000). However, our results do not exclude the possibility that ryanodine-insensitive $\mathrm{Ca}^{2+}$ stores in the postsynaptic cell are necessary for LTD.

\section{LTD depends on T- or R-type, but not L-type, voltage-gated $\mathrm{Ca}^{2+}$ channels}

RyRs can participate in a form of $\mathrm{Ca}^{2+}$ store mobilization known as $\mathrm{Ca}^{2+}$-induced $\mathrm{Ca}^{2+}$ release (CICR). In this process, $\mathrm{Ca}^{2+}$ influx through a plasma membrane channel triggers the subsequent release of $\mathrm{Ca}^{2+}$ from internal stores through RyRs. In cardiac muscle, $\mathrm{Ca}^{2+}$ influx through the L-type voltage-gated $\mathrm{Ca}^{2+}$ channel (VGCC) has been shown to be the dominant mechanism for providing RyRs with this trigger source of $\mathrm{Ca}^{2+}$ (Ogawa et al., 1999). However, additional sources, including influx through low voltage-activated $\mathrm{T}$-type $\mathrm{Ca}^{2+}$ channels, have been implicated under certain situations (Ogawa et al., 1999). To test what mechanisms may be at work in CA3-CA3 synapses during the induction of LTD, we repeated our paired whole-cell recording induction protocol with the L-type VGCC antagonist nitrendipine present in the bath solution. Application of nitrendipine (5 $\mu \mathrm{M})$ did not prevent the induction of LTD, because the average EPSC was reduced to $22 \pm 9 \%$ of baseline ( $n=3$ pairs; $p<0.01$ ) (Fig. $3 A, C$ ). In contrast, bath application of $50 \mu \mathrm{M} \mathrm{Ni}^{2+}$, a concentration that is thought to be a relatively selective T- or R-type VGCC antagonist (Fox et al., 1987; Turner et al., 1995; Huguenard, 1996), prevented the induction of LTD. Fifteen minutes after the LTD induction protocol was delivered in the presence of $\mathrm{Ni}^{2+}$, the EPSC remained at $96 \pm 11 \%$ of its initial value $(n=6$ pairs; $p>0.57$ ) (Fig. $3 B, C$ ). This is in accordance with evidence that T-type VGCCs are required for the induction of LTD at several other synapses in the hippocampus (Christie et al., 1997; Oliet et al., 1997; Wang et al., 1997).

Although N- and P/Q-type VGCCs are believed to mediate fast synaptic transmission between most central neurons, less is known about the role of T- and R-type VGCCs (Turner et al., 1995; Meir et al., 1999). In light of our data demonstrating that $\mathrm{Ni}^{2+}$ can prevent LTD induction, we examined its effect on basal synaptic transmission at CA3-CA3 synapses. We discovered that $50 \mu \mathrm{M} \mathrm{Ni}^{2+}$ inhibited the EPSC to $68 \pm 7 \%(n=4$ cells; $p<0.01)$ of its initial level (data not shown), suggesting that T- or R-type VGCCs might contribute to transmitter release at this synapse. This result complicates the interpretation of our finding that $\mathrm{Ni}^{2+}$ blocked the induction of LTD. Thus, blockade of the T- or R-type channels could act to block induction of LTD either by inhibiting $\mathrm{Ca}^{2+}$ release from internal presynaptic stores or by reducing the extent of postsynaptic activity required to trigger postsynaptic signal transduction cascades (because of the reduction in the EPSC). Results presented below using $\mathrm{Ca}^{2+}$ imaging, however, do suggest a contribution of T- or R-type channels to $\mathrm{Ca}^{2+}$ release from presynaptic stores.

\section{Presynaptic terminal $\mathrm{Ca}^{2+}$ rises in two phases during the LTD protocol}

To test directly whether or not the LTD induction protocol mobilizes $\mathrm{Ca}^{2+}$ from internal presynaptic stores, we used TPLSM to image $\mathrm{Ca}^{2+}$ transients in individual presynaptic terminals from CA3 pyramidal neurons. We loaded presynaptic CA3 neurons with the $\mathrm{Ca}^{2+}$ indicator Oregon Green 488 BAPTA-1 $(500 \mu \mathrm{M})$ in 

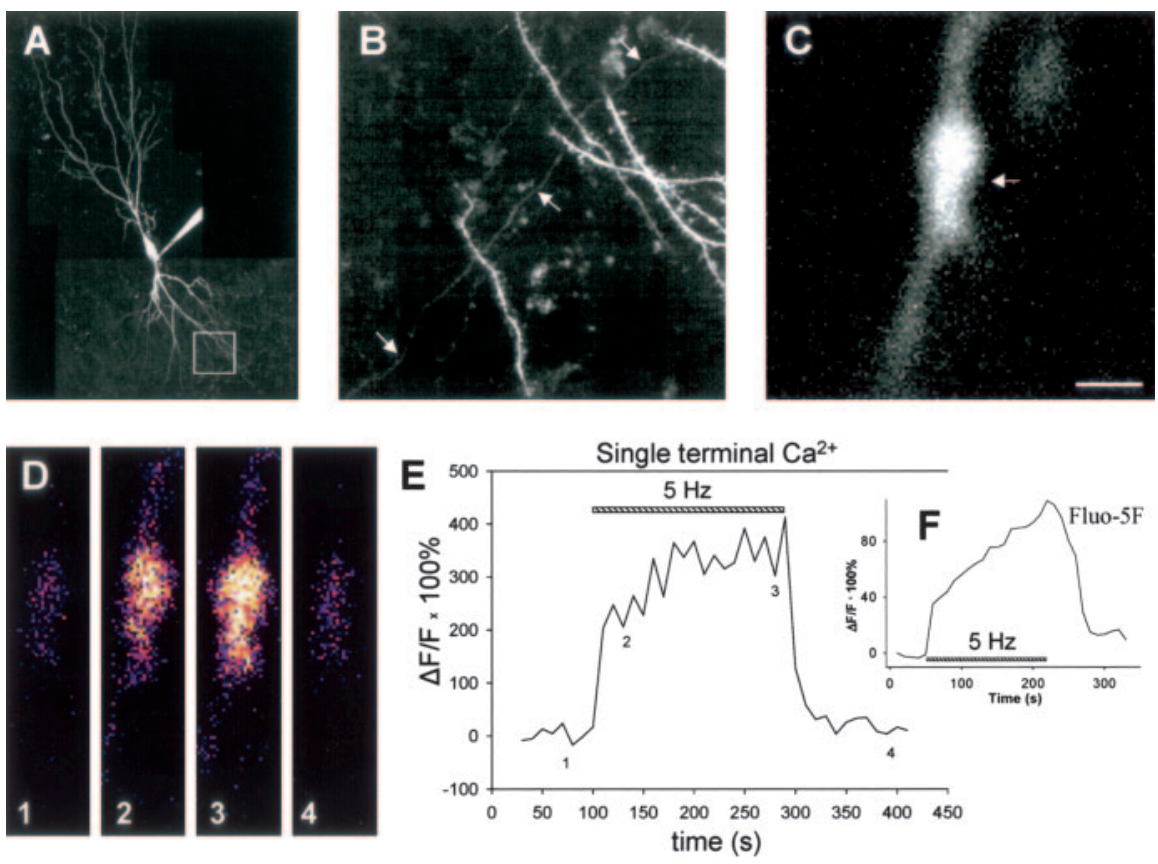

Figure 4. Presynaptic terminal $\mathrm{Ca}^{2+}$ rises in two distinct phases during the LTD induction protocol. $A$, Image of a CA3 pyramidal neuron filled with Oregon Green 488 BAPTA-1. The white box delineates the approximate region shown at higher magnification in B. Scale bar (in C), $50 \mu \mathrm{m}$. B, Basal dendritic region showing thin, smooth axons and thicker, spiny dendrites. The arrows point to an example of one axon crossing from top right to bottom left of field. Scale bar (in $C), 10 \mu \mathrm{m}$. C, High-magnification view of presynaptic terminal (arrow). Scale bar, $1 \mu \mathrm{m}$. D, Single images taken from the terminal shown in $C$, before (1), during the beginning (2), during the end (3), and after (4) the LTD induction protocol. Fluorescence changes coded with a thermal look-up table, small changes coded by "cooler" colors, and larger changes coded by "warmer" colors are shown. Scale bar (in C), $1 \mu \mathrm{m} . E$, $\mathrm{Ca}^{2+}$ rise measured as $\Delta F / F$ (change in fluorescence intensity divided by initial baseline fluorescence intensity) in the terminal shown in (during the LTD induction protocol. The striped bar marks delivery of LTD induction protocol ( $5 \mathrm{~Hz}$ stimulation for $3 \mathrm{~min}$ ). The numbers along the trace show times at which images in D were obtained. $F$, Inset, Presynaptic $\mathrm{Ca}^{2+}$ signal during induction of LTD detected in a cell loaded with $300 \mu \mathrm{m}$ Fluo-5F, a relatively low-affinity $\mathrm{Ca}^{2+}$ dye. A similar fast and slow component to the $\mathrm{Ca}^{2+}$ signal is detected. Data were averaged from seven cells.

the pipette solution under whole-cell recording conditions. After $\sim 1$ hr of whole-cell recording, portions of the axonal arbor could be observed interspersed among spiny basal dendrites (Fig. 4A). Based on their small diameter, smooth appearance, and presence of varicosities, axons were clearly distinguishable from dendrites (Fig. $4 B, C$ ). A previous study on the same preparation has shown that the vast majority of these varicosities are presynaptic terminals of en passant synapses (Emptage et al., 2001).

Imaging of presynaptic terminals of a CA3 neuron during the LTD induction protocol (APs at $5 \mathrm{~Hz}$ for $3 \mathrm{~min}$ ) revealed a large increase in terminal $\mathrm{Ca}^{2+}$ with two distinct phases (Figs. $4 D, E$, $5 A$ ). A fast rising phase is complete within $10 \mathrm{sec}$ of the start of the $3 \mathrm{~min}$ period of $5 \mathrm{~Hz}$ stimulation (the time resolution of these experiments). During this fast phase, the fluorescence signal significantly increased by $248 \pm 25 \%(n=11 ; p<0.001)$ over its initial resting level. This fast phase is then followed by a slow continuous rise in $\mathrm{Ca}^{2+}$ levels over the remaining 3 min period of $5 \mathrm{~Hz}$ stimulation. During the slow phase, the fluorescence signal significantly increased by an additional $121 \pm 48 \%(n=11 ; p<$ $0.05)$ over its resting level. To examine whether the slow phase was an artifact of altered $\mathrm{Ca}^{2+}$ buffering attributable to the high concentration in the patch pipette of Oregon Green BAPTA-1, which has a high $\mathrm{Ca}^{2+}$ affinity of $170 \mathrm{nM}$, we repeated the measurements with a lower concentration of the low-affinity $\mathrm{Ca}^{2+}$ dye Fluo-5F $\left(K_{\mathrm{d}}=2.3 \mu \mathrm{M}\right)$. We observed a rapid and slow phase of the $\mathrm{Ca}^{2+}$ transient in the presynaptic terminals during the 3 min period of $5 \mathrm{~Hz}$ stimulation using $300 \mu \mathrm{M}$ Fluo-5F in the pipette solution (the lowest concentration that gave a reasonable signal in the presynaptic terminal), essentially identical to the results with Oregon Green BAPTA-1 (Fig. $4 F)$. Thus, we conclude that the slow rise in $\mathrm{Ca}^{2+}$ represents a genuine signal that is not an artifact of our measuring conditions.

\section{The fast $\mathrm{Ca}^{2+}$ signal depends partially on T- or R-type VGCCs, and the slow phase depends on ryanodine-sensitive stores}

To explore a role for release from internal stores in the terminal $\mathrm{Ca}^{2+}$ signal, we imaged the rise in presynaptic $\mathrm{Ca}^{2+}$ during the LTD induction protocol with CPA added to the pipette solution at the same concentration $(30 \mu \mathrm{M})$ that blocked LTD in our paired recording experiments (Fig. $5 B, F)$. Application of CPA did not affect the initial fast phase of the $\mathrm{Ca}^{2+}$ signal. In the presence of CPA, the $\mathrm{Ca}^{2+}$ signal rose initially by $252 \pm 35 \%(n=15 ; p<0.001)$ above its resting level, similar to the value of $248 \%$ measured without CPA (see above) or to the value of $279 \pm 39 \%$ ( $n=$ 5 ; $p<0.001$ ) obtained with a pipette solution containing DMSO, the solvent used to dissolve CPA. However, CPA completely blocked the late slow increase in $\mathrm{Ca}^{2+}$, converting it to a slow decline. In the presence of CPA, the fluorescence decreased by $46 \pm 20 \%$ from its initial peak value during this slow decline $(n=15)$. This is in contrast to, and significantly different from, the slow increase of $121 \%$ determined with our normal pipette solution in the absence of CPA (see above; $p<0.01)$ or to the slow increase of $178 \pm 99 \%(n=5$; $p<0.01)$ observed using the DMSO solution. Presynaptic application of ryanodine ( $300 \mu \mathrm{M}$ in the pipette), at a concentration that blocked LTD, also significantly blocked the slow phase of the $\mathrm{Ca}^{2+}$ increase, converting it to a slowly declining phase (decreasing by $88 \pm 24 \% ; n=5 ; p<0.05$ ) while leaving the fast phase unaffected compared with control (247 $\pm 39 \%$ increase; $n=5$, $p>0.98$ ) (Fig. 5C,F). In parallel experiments using the lowaffinity calcium indicator Fluo-5F described above, bath application of ryanodine $(10 \mu \mathrm{M})$ also blocked the slow phase but not the fast phase of the $\mathrm{Ca}^{2+}$ signal (data not shown).

What might provide the $\mathrm{Ca}^{2+}$ trigger for the RyR-mediated slow rise in terminal $\mathrm{Ca}^{2+}$ ? In light of our pharmacological experiments on LTD, we tested the involvement of NMDARs or T-type/R-type VGCCs using bath application of APV or $\mathrm{Ni}^{2+}$, respectively. Because LTD is blocked by D-APV, a finding normally attributable to postsynaptic NMDAR activation, we wondered whether presynaptic NMDARs might also be involved, as has been recently suggested for cerebellar LTD (Casado et al., 2002). However, we found that D-APV $(50 \mu \mathrm{M})$, applied in the bath at the same concentration that blocked LTD, had no effect on either the fast phase ( $286 \pm 35 \%$ increase; $n=3 ; p>0.47$ ) or slow phase ( $72 \pm 48 \%$ increase; $n=3 ; p>0.62$ ) of the $\mathrm{Ca}^{2+}$ signal compared with control (Fig. $5 D, F$ ). In contrast, bath application of the T- and R-type VGCC antagonist $\mathrm{Ni}^{2+}$ at the same concentration that blocked LTD $(50 \mu \mathrm{M})$ significantly 

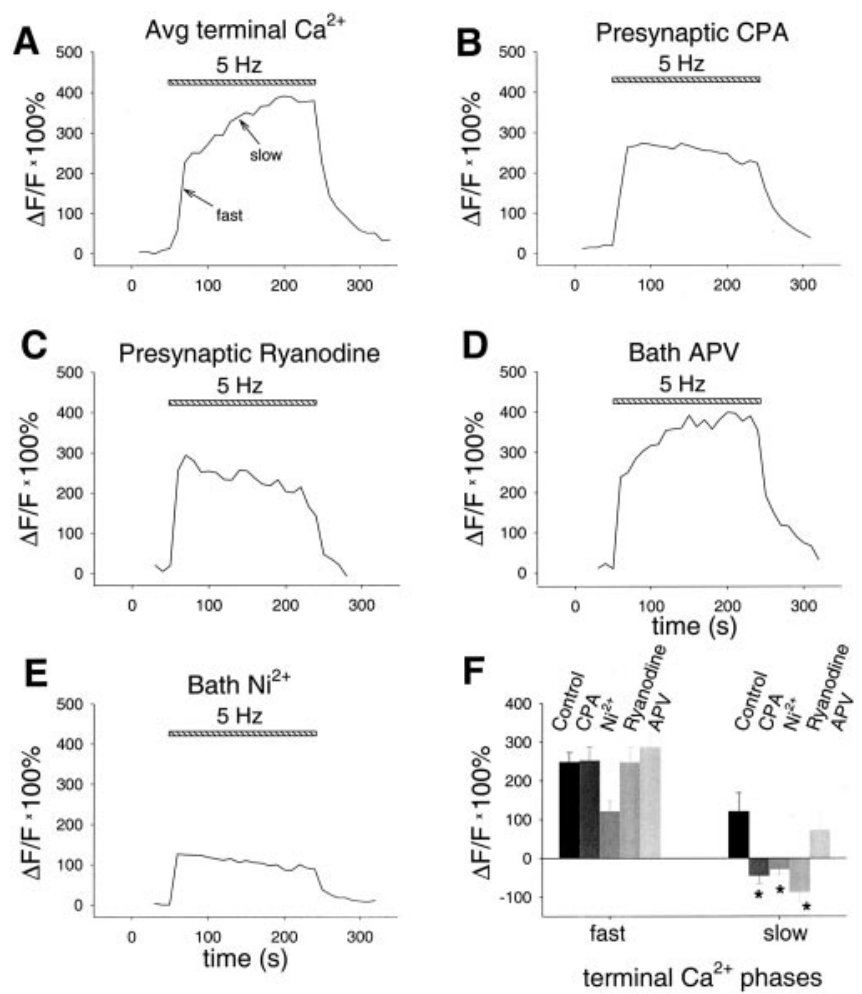

Figure 5. Slow phase of $\mathrm{Ca}^{2+}$ signal depends on release from presynaptic ryanodinesensitive stores, and the fast phase depends partially on influx via T-type or R-type VGCCs. A, Average presynaptic terminal $\mathrm{Ca}^{2+}$ rise during LTD induction protocol $(n=11)$. Arrows point to fast and slow phases. Selective presynaptic application of CPA $(30 \mu \mathrm{m} ; n=15 ; B)$ or ryanodine $(300 \mu \mathrm{m} ; n=5 ;$ C ) selectively inhibits the slow phase. D, Bath application of D-APV $(50 \mu \mathrm{m})$ does not affect either the fast or slow phase $(n=3)$. E, Bath application of $\mathrm{Ni}^{2+}(50 \mu \mathrm{m})$ prevents the slow phase and partially inhibits the fast phase $(n=4)$. F, Summary data from all terminal imaging experiments. The asterisk indicates condition that is significantly different from control ( post hoc Fisher LSD test; $p<0.05$ ).

reduced the initial fast phase of the $\mathrm{Ca}^{2+}$ signal by $50 \%$ (121 \pm $27 \%$ increase; $n=4 ; p<0.05$ ) and completely blocked the slow rise in $\mathrm{Ca}^{2+}$, once again converting it to a slow decline $(28 \pm 14 \%$ decline; $n=4 ; p<0.05$ ) (Fig. $5 E, F$ ).

\section{Presynaptic $\mathrm{Ca}^{2+}$ stores do not contribute to maintained transmitter release during induction of LTD}

What role might $\mathrm{Ca}^{2+}$ release from presynaptic stores play in the induction of LTD? It is generally agreed that release from $\mathrm{Ca}^{2+}$ stores does not contribute to transmitter release evoked by single APs with low-frequency $(\sim 0.1 \mathrm{~Hz})$ stimulation (Reyes and Stanton, 1996; Emptage et al., 2001; Carter et al., 2002). However, it has been suggested that $\mathrm{Ca}^{2+}$ release from internal stores may be involved in short-term synaptic plasticity observed at higher stimulus frequencies (Emptage et al., 2001) (but see Carter et al., 2002). Therefore, $\mathrm{Ca}^{2+}$ release from presynaptic stores may be necessary for maintaining appropriate levels of transmitter release required to produce sufficient postsynaptic activation to induce LTD during the $5 \mathrm{~Hz}$ stimulation protocol.

To test this idea, we measured EPSP size during the $5 \mathrm{~Hz}$ protocol, either in the presence or absence of antagonists of $\mathrm{Ca}^{2+}$ release (Fig. $6 A_{1}-A_{3}$ ). Even in the absence of antagonists, there is a progressive decline in the EPSP amplitude to a steady-state level during the $5 \mathrm{~Hz}$ stimulation, presumably resulting from shortterm depression because of synaptic vesicle depletion. We characterized several properties of the postsynaptic response during 5
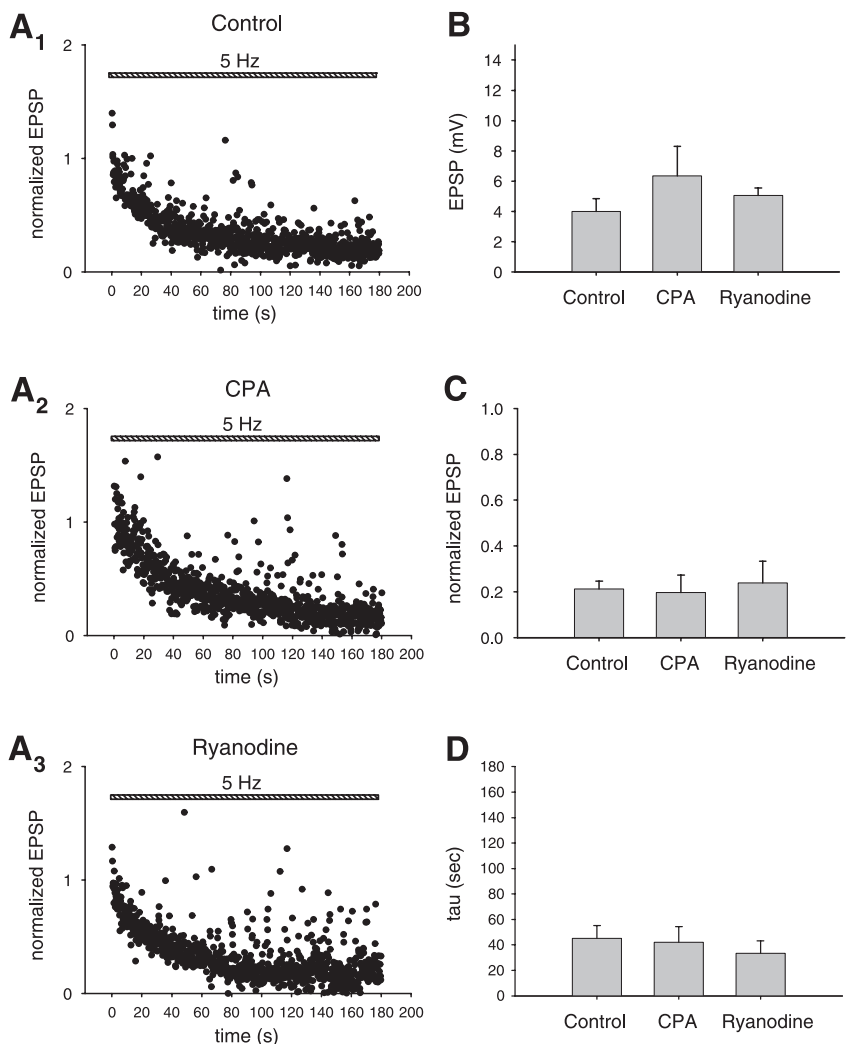

Figure 6. Inhibition of ryanodine-sensitive $\mathrm{Ca}^{2+}$ stores does not reduce postsynaptic depolarization during LTD induction. $A_{1}-A_{3}$, Average (normalized) peak EPSP during LTD induction protocol (striped bar): $A_{1}$, control conditions; $A_{2}$, in the presence of external CPA (2-3 $\left.\mu \mathrm{M}\right) ; A_{3}$, in the presence of external ryanodine $(10 \mu \mathrm{M})$. $B$, Size of initial EPSP (average of first 4 responses) during LTD protocol under the three conditions shown in $A$ (ANOVA; $p>0.40$ ). $C$, Normalized size of steady-state EPSP size at the end of the train (average of last 50 responses) during LTD protocol (ANOVA; $p>0.90$ ). D, Time constant of decay (tau) of EPSP size during LTD induction protocol (ANOVA; $p>0.83$ ).

$\mathrm{Hz}$ stimulation, including the initial EPSP size, final EPSP size, and time constant of decay of the EPSP. Neither ryanodine nor CPA had any effect on synaptic transmission as measured by these three criteria (Fig. $6 B-D$ ). These data suggest that ryanodine-sensitive $\mathrm{Ca}^{2+}$ stores are not required for maintenance of transmitter release during the induction of LTD; rather, these stores must act at a step downstream from the depolarization and activation of the postsynaptic cell.

LTD expression involves a decrease in presynaptic release that is dependent on ryanodine-sensitive stores

The results from our paired recording and imaging experiments argue that presynaptic ryanodine-sensitive stores are required for a slowly rising phase of $\mathrm{Ca}^{2+}$ in the presynaptic terminal that is necessary for the induction of LTD. Given the localization of this slow $\mathrm{Ca}^{2+}$ signal, we next asked whether the expression of CA3CA3 LTD might have a presynaptic component that requires ryanodine-sensitive stores for its induction. Here, we used the styryl dye FM 1-43, a marker of synaptic vesicle cycling dynamics (Betz and Bewick, 1992; Ryan et al., 1993), to track changes in presynaptic function that may be associated with NMDARdependent LTD.

We followed a loading protocol similar to one used previously to investigate presynaptic changes at CA3-CA1 synapses in acute hippocampal slices during LTP (Zakharenko et al., 2001) and during a form of LTD dependent on mGluRs (Zakharenko et al., 


\section{FM 1-43 destaining from presynaptic terminals}
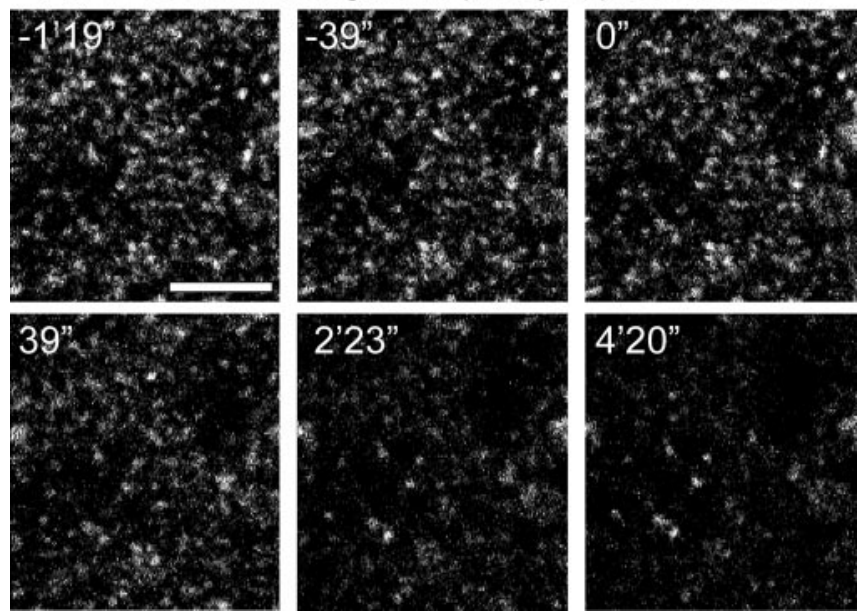

Figure 7. Activity-dependent destaining of FM 1-43 from presynaptic CA3 terminals. Images show FM 1-43 staining for one field of fluorescent puncta that had been previously loaded with dye. Time stamps are marked with reference to the beginning of the $1.5 \mathrm{~Hz}$ destaining stimulation, beginning at time $0^{\prime \prime}$ and continuing for $4^{\prime} 20$." Scale bar, $10 \mu \mathrm{m}$.

2002). FM 1-43 was first loaded into presynaptic terminals by applying the dye $(10 \mu \mathrm{M})$ in the bath solution during synaptic stimulation ( $10 \mathrm{~Hz}$ for $2 \mathrm{~min}$ ), which triggers cycles of exocytosis and endocytosis that results in dye uptake into synaptic vesicles. The dye-loading stimulation was performed in the presence of D-APV $(50 \mu \mathrm{M})$ to block induction of synaptic plasticity at this time. After bath application of the cyclodextrin ADVASEP-7 to remove external dye that is nonspecifically bound to tissue (Kay et al., 1999), brightly fluorescent puncta were visible that corresponded to presynaptic terminals loaded with FM 1-43 (Fig. 7). Presynaptic terminals were then stimulated at $1.5 \mathrm{~Hz}$ in the absence of FM 1-43 (but in the presence of D-APV and ADVASEP-7) to unload dye through triggered exocytosis (Fig. 7 ). Previous studies showed that the rate of dye unloading provides a measure of the efficacy of transmitter release under these conditions (Zakharenko et al., 2001, 2002).

After induction of LTD with the $5 \mathrm{~Hz}$ stimulation protocol (no APV present), the rate of puncta destaining in the CA3 region of slice cultures was significantly decreased (Fig. 8A), consistent with a reduction in the rate of transmitter release. Bath application of D-APV $(50 \mu \mathrm{M})$ during the LTD stimulation protocol, which blocks the induction of LTD (Fig. 1D), also blocked the decrease in FM 1-43 destaining rate (Fig. $8 B$ ). To determine whether the induction of this presynaptic change in FM 1-43 release kinetics required $\mathrm{Ca}^{2+}$ release from presynaptic RyRdependent stores, we delivered the LTD induction protocol in the presence of ryanodine (10 $\mu \mathrm{M}$ in the bath solution). Under these conditions, both the induction of LTD and the depression of FM 1-43 release were blocked (Fig. $8 C$ ). These results demonstrate that NMDAR-dependent LTD at CA3-CA3 synapses involves altered presynaptic function, which requires $\mathrm{Ca}^{2+}$ release from ryanodine-sensitive stores.

\section{Discussion}

Our study reveals that the induction of LTD at CA3-CA3 synapses in the hippocampus requires presynaptic ryanodinesensitive $\mathrm{Ca}^{2+}$ stores. Given the role for such stores during the induction of LTD at other hippocampal synapses (Reyes and Stanton, 1996; Wang et al., 1997; Caillard et al., 2000; Nishiyama et al., 2000), our results indicate the conservation of mechanisms of LTD induction at diverse synapses. Dual whole-cell recordings provided direct evidence that the ryanodine-sensitive stores are required only in the presynaptic neuron and not in the postsynaptic neuron during LTD induction. Calcium imaging experiments demonstrated that the LTD induction protocol recruits a slowly rising component of the presynaptic $\mathrm{Ca}^{2+}$ signal that is attributable to calcium release from ryanodine-sensitive stores. Moreover, this signal is necessary for the induction of LTD and the expression of presynaptic changes in vesicle cycling associated with LTD. It is important to point out, however, that our results do not preclude a role for $\mathrm{Ca}^{2+}$ release from ryanodineinsensitive stores in the postsynaptic cell, for example because of $\mathrm{IP}_{3} \mathrm{Rs}$, in the induction of LTD at these synapses.

Perhaps the simplest model that is consistent with our data are that LTD requires CICR from presynaptic $\mathrm{Ca}^{2+}$ stores through activation of RyRs themselves. Alternatively, the slow phase of the presynaptic $\mathrm{Ca}^{2+}$ signal may actually result from presynaptic $\mathrm{IP}_{3} \mathrm{R}$-dependent $\mathrm{Ca}^{2+}$ release. In this case, the inhibitory effect of ryanodine would be explained if there were a transient opening of the RyRs during the onset of ryanodine application that depleted the $\mathrm{IP}_{3} \mathrm{R}$-dependent $\mathrm{Ca}^{2+}$ stores because of the fact that RyRs and $\mathrm{IP}_{3}$ Rs can coexist in the same stores (Zacchetti et al., 1991; Wang et al., 1995). Finally, release from internal stores may require a cooperative interaction between RyRs and $\mathrm{IP}_{3} \mathrm{Rs}$ (Ashby et al., 2003). According to this model, blockade of either type of release channel would abolish the slow phase.

Our attempts to directly assess the role of $\mathrm{IP}_{3}$-sensitive stores in the induction of LTD were inconclusive. The $\mathrm{IP}_{3} \mathrm{R}$ [and storeoperated channel (SOC)] antagonist 2-aminoethoxydiphenyl borate (2-APB) (Maruyama et al., 1997; Ascher-Landsberg et al., 1999) was toxic to neurons in our slice cultures (concentrations from 5 to $250 \mu \mathrm{M})$. Although we found that the $\mathrm{IP}_{3} \mathrm{R}$ antagonist xestospongin $\mathrm{C}(10 \mu \mathrm{M})$ did not block LTD at this synapse $(n=2$; data not shown), the lack of adequate positive controls make this result difficult to interpret. However, our finding that group I mGluRs, the type most commonly linked to $\mathrm{IP}_{3}$ production, do not participate in this form of LTD suggests that $\mathrm{IP}_{3} \mathrm{R}$-dependent $\mathrm{Ca}^{2+}$ release may not be involved here. This is further consistent with an electron-microscopic study showing a much higher level of expression of RyRs compared with $\mathrm{IP}_{3} \mathrm{Rs}$ in axons of hippocampal neurons (Sharp et al., 1993). Thus, we believe that the simplest interpretation of our experiments is that induction of LTD requires CICR from presynaptic stores mediated by the RyRs themselves.

The slow time course of the $\mathrm{Ca}^{2+}$ signal associated with release from ryanodine-sensitive stores during the induction of LTD is puzzling because the rise in $\mathrm{Ca}^{2+}$ in response to CICR through RyRs is usually quite rapid (Bers, 2002). The RyRs or ryanodine-sensitive stores in CA3 terminals may exist initially in a nonfunctional state and may slowly activate during the $3 \mathrm{~min}$ period of synaptic stimulation during LTD induction. Kuba and colleagues (Narita et al., 1998, 2000) have reported a similar slow ryanodine-sensitive $\mathrm{Ca}^{2+}$ rise in presynaptic terminals of frog motoneurons during a $20-50 \mathrm{~Hz}$ train of stimulation, which they attribute to a "priming" effect of the tetanic stimulation. Liang et al. (2002) have imaged $\mathrm{Ca}^{2+}$ in hippocampal mossy fiber presynaptic terminals during stimulation with short trains of APs. They also suggest that regulation of presynaptic ryanodine-sensitive stores might explain the variable presence of a RyR-dependent delayed component to the $\mathrm{Ca}^{2+}$ signal measured in these terminals.

One possibility is that the stores are initially empty and then slowly fill as $\mathrm{Ca}^{2+}$ enters the terminal through VGCCs during the 
$5 \mathrm{~Hz}$ stimulation. Such an effect would be similar to the slow filling of cardiac $\mathrm{Ca}^{2+}$ stores that underlies a slow increase in cardiac contractility (staircase phenomenon) during a tetanus (Brotto and Creazzo, 1996; Huser et al., 1996). Alternatively, there may be a slow modulation of the RyRs themselves. Two particularly intriguing candidate modulators are nitric oxide and cyclic ADP-ribose, both of which are known to alter RyR function (Zucchi and Ronca-Testoni, 1997). Moreover, pharmacological blockade of either pathway inhibits the induction of LTD at CA3-CA1 synapses (Reyes-Harde et al., 1999). Differences in the basal state of RyR function could explain the conflicting results from different studies arguing either for (Emptage et al., 2001) or against (Carter et al., 2002) a role for store-mediated presynaptic $\mathrm{Ca}^{2+}$ release at pyramidal neuron synapses.

It is also possible that the slow $\mathrm{Ca}^{2+}$ signal is not directly attributable to release from RyR-sensitive stores. Rather, pharmacological interference with RyRdependent store function might lead to secondary changes in $\mathrm{Ca}^{2+}$ signaling. For example, depletion of $\mathrm{Ca}^{2+}$ from RyRsensitive internal stores during the $5 \mathrm{~Hz}$ stimulation may trigger the opening of plasma membrane SOCs, which could give rise to a slow $\mathrm{Ca}^{2+}$ signal (Bouron, 2000; Putney et al., 2001). We have tried to test this hypothesis with the SOC inhibitor 2-APB (Maruyama et al., 1997; AscherLandsberg et al., 1999), but, as reported above, this compound was toxic to our slice cultures at relevant concentrations. A second possibility is that the slow $\mathrm{Ca}^{2+}$ signal is attributable to release from mitochondrial stores (Babcock and Hille, 1998; Kaczmarek, 2000), the filling of which is indirectly affected by inhibition of RyR-sensitive stores (perhaps because of changes in resting $\mathrm{Ca}^{2+}$ levels).

What is the function of the slow ryanodine-sensitive rise in $\mathrm{Ca}^{2+}$ ? One potential clue is that the time course of this slow signal parallels the time course of LTD induction during the $3 \mathrm{~min}$ period of $5 \mathrm{~Hz}$ stimulation. Shorter periods of stimulation (e.g., $30 \mathrm{sec}$ ), which recruit only a small RyR-dependent $\mathrm{Ca}^{2+}$ signal, induce LTP (Winder et al., 1999), not LTD. Thus, the slow $\mathrm{Ca}^{2+}$ rise could serve as an integrator of synaptic activity, informing the presynaptic terminal as to the history of its activity over a time scale of tens of seconds to minutes. The importance of presynaptic signaling is underscored by our finding that LTD is associated with a diminished rate of FM 1-43 release from presynaptic terminals. Given the requirement of postsynaptic NMDAR activation for LTD induction, these results indicate the need for a retrograde messenger that conveys a postsynaptic signal to the presynaptic terminal. In this context, the RyR-dependent slow phase of $\left[\mathrm{Ca}^{2+}\right]_{\mathrm{i}}$ could act as a gate that restricts the action of the retrograde message to those terminals that are coactivated for prolonged periods with postsynaptic NMDAR stimulation. This may explain how a single retrograde messenger, such as nitric oxide, could mediate both LTP (Arancio et al., 1996) and LTD (Reyes-Harde et al., 1999): only LTD-inducing patterns of stimulation would produce a sufficiently prolonged period of presynaptic activity to elicit a sufficiently large ryanodine-sensitive $\mathrm{Ca}^{2+}$ signal to induce LTD, perhaps by gating the response of the presynaptic terminal to nitric oxide, producing depression rather than potentiation. [This explanation may not apply to forms of spike-timing-dependent LTD induced by shorter periods of stimulation (Nishiyama et al., 2000)]. It is unlikely that the slow presynaptic $\mathrm{Ca}^{2+}$ signal is itself generated by the retrograde messenger because the slow $\mathrm{Ca}^{2+}$ rise was not blocked by inhibition of NMDARs with D-APV (Fig. 5D).

The RyR-dependent presynaptic $\mathrm{Ca}^{2+}$ signal may also act to increase the synapse specificity of homosynaptic LTD. A freely diffusible retrograde messenger could impinge on both presynaptic terminals that are activated during the induction of plasticity and presynaptic terminals that are not active during the induction stimulation. If induction of presynaptic LTD required the conjoint action of the retrograde message with the slow $\mathrm{Ca}^{2+}$ signal, LTD would be restricted to only those synapses that were active during its induction. Recently, Nishiyama et al. (2000) proposed a similar role for postsynaptic RyR-sensitive stores because inclusion of ryanodine in the postsynaptic electrode blocked homosynaptic LTD in CA1 neurons induced by spike 
timing and resulted in the appearance of heterosynaptic LTD. Our results and those of Stanton et al. (2001, 2003), demonstrating a presynaptic component to NMDAR-dependent LTD, raise the interesting question as to its behavioral relevance. Selective deletion of RyRs from presynaptic neurons using region-specific knock-outs would provide a potentially powerful system for exploring the cellular and behavioral consequences of this regulatory pathway.

\section{References}

Arancio O, Kiebler M, Lee CJ, Lev-Ram V, Tsien RY, Kandel ER, Hawkins RD (1996) Nitric oxide acts directly in the presynaptic neuron to produce long-term potentiation in cultured hippocampal neurons. Cell 87:1025-1035.

Ascher-Landsberg J, Saunders T, Elovitz M, Phillippe M (1999) The effects of 2-aminoethoxydiphenyl borate, a novel inositol 1,4,5-trisphosphate receptor modulator on myometrial contractions. Biochem Biophys Res Commun 264:979-982.

Ashby MC, Petersen OH, Tepikin AV (2003) Spatial characterisation of ryanodine-induced calcium release in mouse pancreatic acinar cells. Biochem J 369:441-445.

Babcock DF, Hille B (1998) Mitochondrial oversight of cellular $\mathrm{Ca}^{2+}$ signaling. Curr Opin Neurobiol 8:398-404.

Berridge MJ (1998) Neuronal calcium signaling. Neuron 21:13-26.

Berridge MJ, Bootman MD, Roderick HL (2003) Calcium signalling: dynamics, homeostasis and remodelling. Nat Rev Mol Cell Biol 4:517-529.

Bers DM (2002) Cardiac excitation-contraction coupling. Nature 415:198-205.

Betz WJ, Bewick GS (1992) Optical analysis of synaptic vesicle recycling at the frog neuromuscular junction. Science 255:200-203.

Bolshakov VY, Siegelbaum SA (1994) Postsynaptic induction and presynaptic expression of hippocampal long-term depression. Science 264:1148-1152.

Bouron A (2000) Activation of a capacitative $\mathrm{Ca}(2+)$ entry pathway by store depletion in cultured hippocampal neurones. FEBS Lett 470:269-272.

Brotto MA, Creazzo TL (1996) $\mathrm{Ca}^{2+}$ transients in embryonic chick heart: contributions from $\mathrm{Ca}^{2+}$ channels and the sarcoplasmic reticulum. Am J Physiol 270:H518-H525.

Caillard O, Ben-Ari Y, Gaiarsa JL (2000) Activation of presynaptic and postsynaptic ryanodine-sensitive calcium stores is required for the induction of long-term depression at GABAergic synapses in the neonatal rat hippocampus amphetamine. J Neurosci 20:RC94(1-5).

Carter AG, Vogt KE, Foster KA, Regehr WG (2002) Assessing the role of calcium-induced calcium release in short-term presynaptic plasticity at excitatory central synapses. J Neurosci 22:21-28.

Casado M, Isope P, Ascher P (2002) Involvement of presynaptic N-methylD-aspartate receptors in cerebellar long-term depression. Neuron 33:123-130.

Christie BR, Schexnayder LK, Johnston D (1997) Contribution of voltagegated $\mathrm{Ca}^{2+}$ channels to homosynaptic long-term depression in the CA1 region in vitro. J Neurophysiol 77:1651-1655.

Daniel H, Levenes C, Fagni L, Conquet F, Bockaert J, Crepel F (1999) Inositol-1,4,5-trisphosphate-mediated rescue of cerebellar long-term depression in subtype 1 metabotropic glutamate receptor mutant mouse. Neuroscience 92:1-6.

Debanne D, Gahwiler BH, Thompson SM (1998) Long-term synaptic plasticity between pairs of individual CA3 pyramidal cells in rat hippocampal slice cultures. J Physiol (Lond) 507:237-247.

Dudek SM, Bear MF (1992) Homosynaptic long-term depression in area CA1 of hippocampus and effects of $N$-methyl-D-aspartate receptor blockade. Proc Natl Acad Sci USA 89:4363-4367.

Emptage N, Bliss TV, Fine A (1999) Single synaptic events evoke NMDA receptor-mediated release of calcium from internal stores in hippocampal dendritic spines. Neuron 22:115-124.

Emptage NJ, Reid CA, Fine A (2001) Calcium stores in hippocampal synaptic boutons mediate short-term plasticity, store-operated $\mathrm{Ca}^{2+}$ entry, and spontaneous transmitter release. Neuron 29:197-208.

Finch EA, Augustine GJ (1998) Local calcium signalling by inositol-1,4,5trisphosphate in Purkinje cell dendrites. Nature 396:753-756.
Fitzjohn SM, Collingridge GL (2002) Calcium stores and synaptic plasticity. Cell Calcium 32:405-411.

Fox AP, Nowycky MC, Tsien RW (1987) Single-channel recordings of three types of calcium channels in chick sensory neurones. J Physiol (Lond) 394:173-200.

Futatsugi A, Kato K, Ogura H, Li ST, Nagata E, Kuwajima G, Tanaka K, Itohara S, Mikoshiba K (1999) Facilitation of NMDAR-independent LTP and spatial learning in mutant mice lacking ryanodine receptor type 3. Neuron 24:701-713.

Gasparini F, Lingenhohl K, Stoehr N, Flor PJ, Heinrich M, Vranesic I, Biollaz M, Allgeier H, Heckendorn R, Urwyler S, Varney MA, Johnson EC, Hess SD, Rao SP, Sacaan AI, Santori EM, Velicelebi G, Kuhn R (1999) 2-Methyl-6-(phenylethynyl)-pyridine (MPEP), a potent, selective and systemically active mGlu5 receptor antagonist. Neuropharmacology 38:1493-1503.

Harvey J, Collingridge GL (1992) Thapsigargin blocks the induction of long-term potentiation in rat hippocampal slices. Neurosci Lett 139:197-200.

Huguenard JR (1996) Low-threshold calcium currents in central nervous system neurons. Annu Rev Physiol 58:329-348.

Huser J, Lipsius SL, Blatter LA (1996) Calcium gradients during excitationcontraction coupling in cat atrial myocytes. J Physiol (Lond) 494:641-651.

Inoue T, Kato K, Kohda K, Mikoshiba K (1998) Type 1 inositol 1,4,5trisphosphate receptor is required for induction of long-term depression in cerebellar Purkinje neurons. J Neurosci 18:5366-5373.

Kaczmarek LK (2000) Mitochondrial memory banks. Calcium stores keep a record of neuronal stimulation. J Gen Physiol 115:347-350.

Kay AR, Alfonso A, Alford S, Cline HT, Holgado AM, Sakmann B, Snitsarev VA, Stricker TP, Takahashi M, Wu LG (1999) Imaging synaptic activity in intact brain and slices with FM1-43 in C. elegans, lamprey, and rat. Neuron 24:809-817.

Kurebayashi N, Ogawa Y (1991) Discrimination of Ca(2+)-ATPase activity of the sarcoplasmic reticulum from actomyosin-type ATPase activity of myofibrils in skinned mammalian skeletal muscle fibres: distinct effects of cyclopiazonic acid on the two ATPase activities. J Muscle Res Cell Motil 12:355-365.

Liang Y, Yuan LL, Johnston D, Gray R (2002) Calcium signaling at single mossy fiber presynaptic terminals in the rat hippocampus. J Neurophysiol 87:1132-1137.

Llano I, Gonzalez J, Caputo C, Lai FA, Blayney LM, Tan YP, Marty A (2000) Presynaptic calcium stores underlie large-amplitude miniature IPSCs and spontaneous calcium transients. Nat Neurosci 3:1256-1265.

Maruyama T, Kanaji T, Nakade S, Kanno T, Mikoshiba K (1997) 2APB, 2-aminoethoxydiphenyl borate, a membrane-penetrable modulator of Ins(1,4,5)P3-induced $\mathrm{Ca}^{2+}$ release. J Biochem (Tokyo) 122:498-505.

Meir A, Ginsburg S, Butkevich A, Kachalsky SG, Kaiserman I, Ahdut R, Demirgoren S, Rahamimoff R (1999) Ion channels in presynaptic nerve terminals and control of transmitter release. Physiol Rev 79:1019-1088.

Montgomery JM, Madison DV (2002) State-dependent heterogeneity in synaptic depression between pyramidal cell pairs. Neuron 33:765-777.

Montgomery JM, Pavlidis P, Madison DV (2001) Pair recordings reveal allsilent synaptic connections and the postsynaptic expression of long-term potentiation. Neuron 29:691-701.

Moroni F, Lombardi G, Thomsen C, Leonardi P, Attucci S, Peruginelli F, Torregrossa SA, Pellegrini-Giampietro DE, Luneia R, Pellicciari R (1997) Pharmacological characterization of 1-aminoindan-1,5-dicarboxylic acid, a potent mGluR1 antagonist. J Pharmacol Exp Ther 281:721-729.

Mulkey RM, Malenka RC (1992) Mechanisms underlying induction of homosynaptic long-term depression in area CA1 of the hippocampus. Neuron 9:967-975.

Nakamura T, Barbara JG, Nakamura K, Ross WN (1999) Synergistic release of $\mathrm{Ca}^{2+}$ from IP3-sensitive stores evoked by synaptic activation of mGluRs paired with backpropagating action potentials. Neuron 24:727-737.

Narita K, Akita T, Osanai M, Shirasaki T, Kijima H, Kuba K (1998) $\mathrm{A} \mathrm{Ca}^{2+}$ induced $\mathrm{Ca}^{2+}$ release mechanism involved in asynchronous exocytosis at frog motor nerve terminals. J Gen Physiol 112:593-609.

Narita K, Akita T, Hachisuka J, Huang S, Ochi K, Kuba K (2000) Functional coupling of $\mathrm{Ca}(2+)$ channels to ryanodine receptors at presynaptic terminals. Amplification of exocytosis and plasticity. J Gen Physiol 115:519-532. 
Nishiyama M, Hong K, Mikoshiba K, Poo MM, Kato K (2000) Calcium stores regulate the polarity and input specificity of synaptic modification. Nature 408:584-588.

Ogawa Y, Kurebayashi N, Murayama T (1999) Ryanodine receptor isoforms in excitation-contraction coupling. Adv Biophys 36:27-64.

Oliet SH, Malenka RC, Nicoll RA (1997) Two distinct forms of long-term depression coexist in CA1 hippocampal pyramidal cells. Neuron 18:969-982.

Pavlidis P, Madison DV (1999) Synaptic transmission in pair recordings from CA3 pyramidal cells in organotypic culture. J Neurophysiol 81:2787-2797.

Pavlidis P, Montgomery J, Madison DV (2000) Presynaptic protein kinase activity supports long-term potentiation at synapses between individual hippocampal neurons. J Neurosci 20:4497-4505.

Putney Jr JW, Broad LM, Braun FJ, Lievremont JP, Bird GS (2001) Mechanisms of capacitative calcium entry. J Cell Sci 114:2223-2229.

Reyes M, Stanton PK (1996) Induction of hippocampal long-term depression requires release of $\mathrm{Ca}^{2+}$ from separate presynaptic and postsynaptic intracellular stores. J Neurosci 16:5951-5960.

Reyes-Harde M, Potter BV, Galione A, Stanton PK (1999) Induction of hippocampal LTD requires nitric-oxide-stimulated PKG activity and $\mathrm{Ca}^{2+}$ release from cyclic ADP-ribose-sensitive stores. J Neurophysiol 82:1569-1576.

Rose CR, Konnerth A (2001) Stores not just for storage. Intracellular calcium release and synaptic plasticity. Neuron 31:519-522.

Ryan TA, Reuter H, Wendland B, Schweizer FE, Tsien RW, Smith SJ (1993) The kinetics of synaptic vesicle recycling measured at single presynaptic boutons. Neuron 11:713-724.

Sharp AH, McPherson PS, Dawson TM, Aoki C, Campbell KP, Snyder SH (1993) Differential immunohistochemical localization of inositol 1,4,5trisphosphate- and ryanodine-sensitive $\mathrm{Ca}^{2+}$ release channels in rat brain. J Neurosci 13:3051-3063.

Stanton PK, Sejnowski TJ (1989) Associative long-term depression in the hippocampus induced by hebbian covariance. Nature 339:215-218.

Stanton PK, Heinemann U, Muller W (2001) FM1-43 imaging reveals cGMP-dependent long-term depression of presynaptic transmitter release. J Neurosci 21:RC167(1-6).

Stanton PK, Winterer J, Bailey CP, Kyrozis A, Raginov I, Laube G, Veh RW,
Nguyen CQ, Muller W (2003) Long-term depression of presynaptic release from the readily releasable vesicle pool induced by NMDA receptordependent retrograde nitric oxide. J Neurosci 23:5936-5944.

Stoppini L, Buchs PA, Muller D (1991) A simple method for organotypic cultures of nervous tissue. J Neurosci Methods 37:173-182.

Svoboda K, Mainen ZF (1999) Synaptic $\left[\mathrm{Ca}^{2+}\right]$ : intracellular stores spill their guts. Neuron 22:427-430.

Takechi H, Eilers J, Konnerth A (1998) A new class of synaptic response involving calcium release in dendritic spines. Nature 396:757-760.

Turner TJ, Lampe RA, Dunlap K (1995) Characterization of presynaptic calcium channels with omega-conotoxin MVIIC and omegagrammotoxin SIA: role for a resistant calcium channel type in neurosecretion. Mol Pharmacol 47:348-353.

Wang X, Lau F, Li L, Yoshikawa A, van Breemen C (1995) Acetylcholinesensitive intracellular $\mathrm{Ca}^{2+}$ store in fresh endothelial cells and evidence for ryanodine receptors. Circ Res 77:37-42.

Wang Y, Rowan MJ, Anwyl R (1997) Induction of LTD in the dentate gyrus in vitro is NMDA receptor independent, but dependent on $\mathrm{Ca}^{2+}$ influx via low-voltage-activated $\mathrm{Ca}^{2+}$ channels and release of $\mathrm{Ca}^{2+}$ from intracellular stores. J Neurophysiol 77:812-825.

Winder DG, Martin KC, Muzzio IA, Rohrer D, Chruscinski A, Kobilka B, Kandel ER (1999) ERK plays a regulatory role in induction of LTP by theta frequency stimulation and its modulation by beta-adrenergic receptors. Neuron 24:715-726.

Zacchetti D, Clementi E, Fasolato C, Lorenzon P, Zottini M, Grohovaz F, Fumagalli G, Pozzan T, Meldolesi J (1991) Intracellular $\mathrm{Ca}^{2+}$ pools in PC12 cells. A unique, rapidly exchanging pool is sensitive to both inositol 1,4,5-trisphosphate and caffeine-ryanodine. J Biol Chem 266:20152-20158.

Zakharenko SS, Zablow L, Siegelbaum SA (2001) Visualization of changes in presynaptic function during long-term synaptic plasticity. Nat Neurosci 4:711-717.

Zakharenko SS, Zablow L, Siegelbaum SA (2002) Altered presynaptic vesicle release and cycling during mGluR-dependent LTD. Neuron 35:1099-1110.

Zucchi R, Ronca-Testoni S (1997) The sarcoplasmic reticulum $\mathrm{Ca}^{2+}$ channel/ryanodine receptor: modulation by endogenous effectors, drugs and disease states. Pharmacol Rev 49:1-51. 